\title{
Primary cutaneous mucormycosis developing after incision and drainage of a subcutaneous abscess in an immunocompetent host
}

\author{
Norman Beatty, ${ }^{1}$ Mayar Al Mohajer ${ }^{2}$
}

${ }^{1}$ Department of Internal Medicine, University of Arizona College of Medicine Tucson at South Campus, Tucson, Arizona, USA

${ }^{2}$ Department of Infectious Diseases, University of Arizona College of Medicine Tucson, Tucson, Arizona, USA

\section{Correspondence to} Dr Norman Beatty, nbeatty@email.arizona.edu

Accepted 12 December 2015

\section{DESCRIPTION}

A 35 -year-old man with no known medical history presented to an outpatient clinic, with a warm, erythematous, tender skin lesion that was draining purulent fluid, on his left medial lower extremity (figure 1). The patient denied any similar events and was lacking other systemic symptoms. Vital signs were normal. The remainder of the physical examination was benign. Incision of the lesion yielded purulent drainage that was sent for culture. The wound was then washed with sterile saline and packed with cotton gauze; an elasticised dressing was applied over the top. The patient was given oral doxycycline with instructions to return the next day. Approximately $12 \mathrm{~h}$ later, the patient returned with symptoms of worsening left leg pain. The external dressing was removed from the lesion, revealing a black necrotic centre with expanding erythematous borders (figures 2 and 3). Purulent 'fuzzy'-appearing discharge was noted when the cotton gauze packing was removed. The patient was immediately sent to the hospital and taken to the operating theatre for surgical debridement. Histopathology subsequently revealed the presence of broad non-septate fungal elements (figure 4) throughout - thus a second surgical debridement (figure 5) was required to clear all tissue margins of these fungal elements. Our patient was diagnosed with primary cutaneous mucormycosis (PCM) and intravenous liposomal amphotericin B (LAmB) was initiated. Bacterial culture of the purulent fluid from the wound grew methicillin-resistant Staphylococcus aureus, and the patient was treated accordingly with oral doxycycline for 1 week. He received 2 days of intravenous $\mathrm{LAmB}$ and was discharged with an 8-week course of daily extended-release oral posaconazole $(300 \mathrm{mg})$

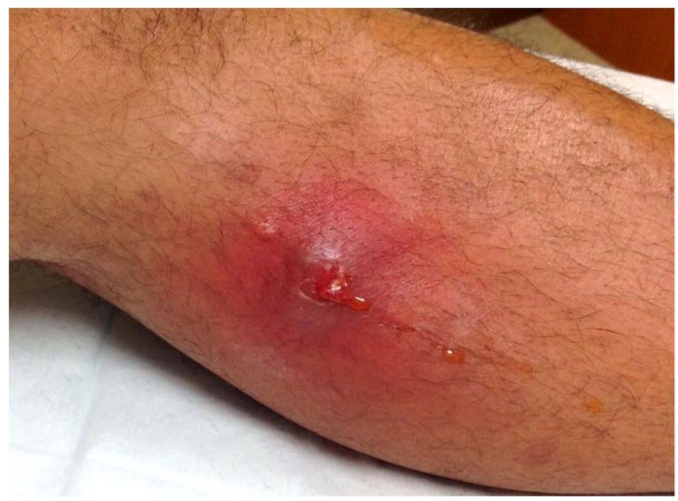

Figure 1 Subcutaneous abscess on left medial lower extremity.

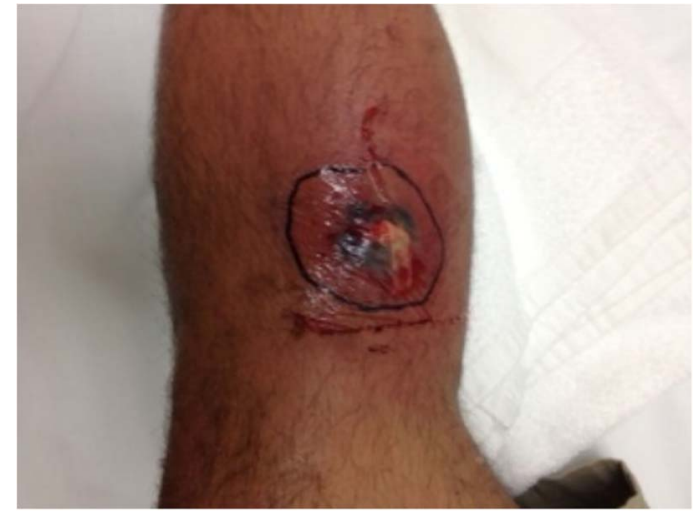

Figure 2 Prior to removal of the cotton gauze packing, a black necrotic centre with expanded erythematous borders is visualised through the clear elasticised dressing.

salvage therapy. After 12 weeks, the wound was completely healed with the assistance of a temporary wound vacuum device.

PCM is caused by invasive filamentous fungi belonging to the order Mucorales. ${ }^{1}$ They are commonly found in the soil and are associated with decaying wood and organic matter. ${ }^{1}{ }^{2}$ PCM can

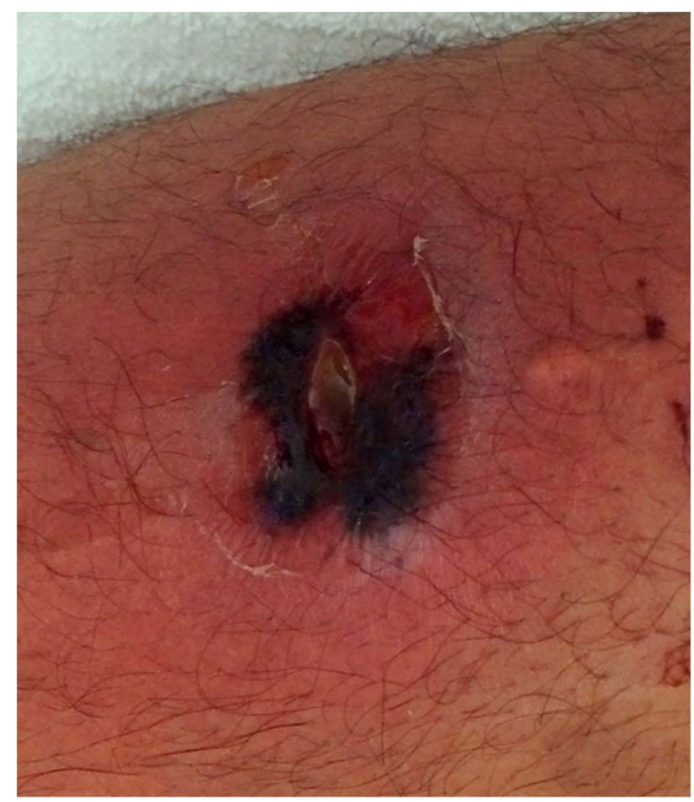

Figure 3 Necrosis with a 'fuzzy' discharge and black irregular borders is seen at the incision site after the removal of the cotton gauze packing and elasticised dressing. 


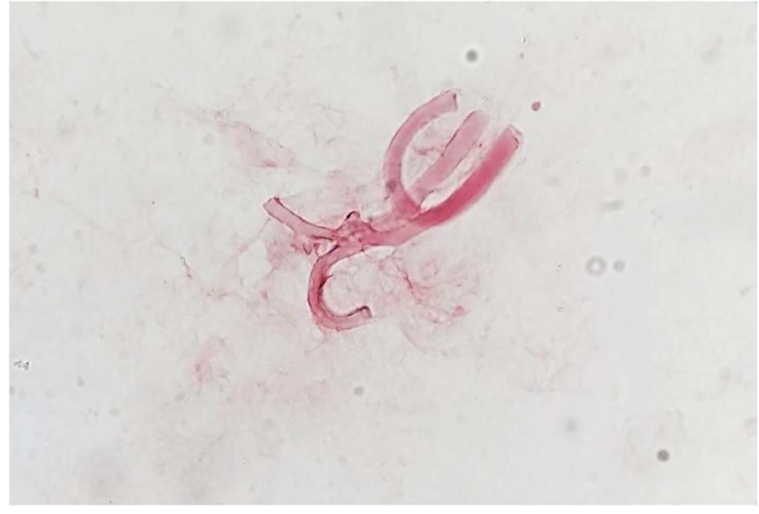

Figure $4 \mathrm{KOH} 10 \%$ preparation of tissue samples revealed broad non-septate fungal elements visualised under light microscopy.

develop after inoculation of Mucorales sporangiospores through disrupted mucocutaneous barriers. ${ }^{1}$ PCM largely occurs in immunocompetent patients. ${ }^{1}{ }^{2}$ Risk factors include healthcare-related processes such as catheter and adhesive tape placement, injections, ostomy bags, contaminated wooden tongue depressors and cotton clothing. ${ }^{1}$ PCM has also been demonstrated in scenarios involving high-impact trauma such as motor vehicle accidents, natural disasters and combat-related events. $^{1}{ }^{2}$ Diabetes mellitus, immunosuppressive conditions, neutropaenia, ketoacidosis, burns, haematological malignancy, iron-overload states and treatment with deferoxamine, are underlying conditions associated with PCM. ${ }^{1}{ }^{2}$ Our patient was deemed immunocompetent after our investigations, which included HIV testing, did not reveal evidence of any of these underlying conditions. PCM is diagnosed when histopathological analysis reveals broad $(10-20 \mu \mathrm{m})$ coenocytic (aseptate) hyphal elements, visualised in the tissue specimen. ${ }^{12}$ Similarly to our patient, fungal culture can yield no growth ${ }^{2}$ and the diagnosis is generally made with direct visualisation. PCR-based techniques are now readily available to identify and confirm the culprit species when needed. ${ }^{2}$ A combination of surgical debridement and intravenous LAmB is the gold standard for initial treatment. ${ }^{2}$ Posaconazole is highly active against Mucorales spp, and is used in combination with LAmB or as salvage therapy to prevent recurrence. ${ }^{13}$

\section{Learning points}

- Immunocompetent patients are at risk for developing primary cutaneous mucormycosis after percutaneous inoculation of spores.

- Risk factors for immunocompetent patients include contaminated traumatic wounds, burns, surgical sites and wound dressing materials.

- A combination of surgical debridement and intravenous liposomal amphotericin B is the gold standard for initial treatment.

- Salvage therapy with oral posaconazole has been used to help prevent recurrence of this infection.

Contributors NB was responsible for obtaining the history, acquiring the images, patient consent for publication and generation of the original manuscript. MAM was responsible for reviewing and making revisions to the original manuscript.

Competing interests None declared.

Patient consent Obtained.
Figure 5 Left medial lower extremity after second surgical debridement.

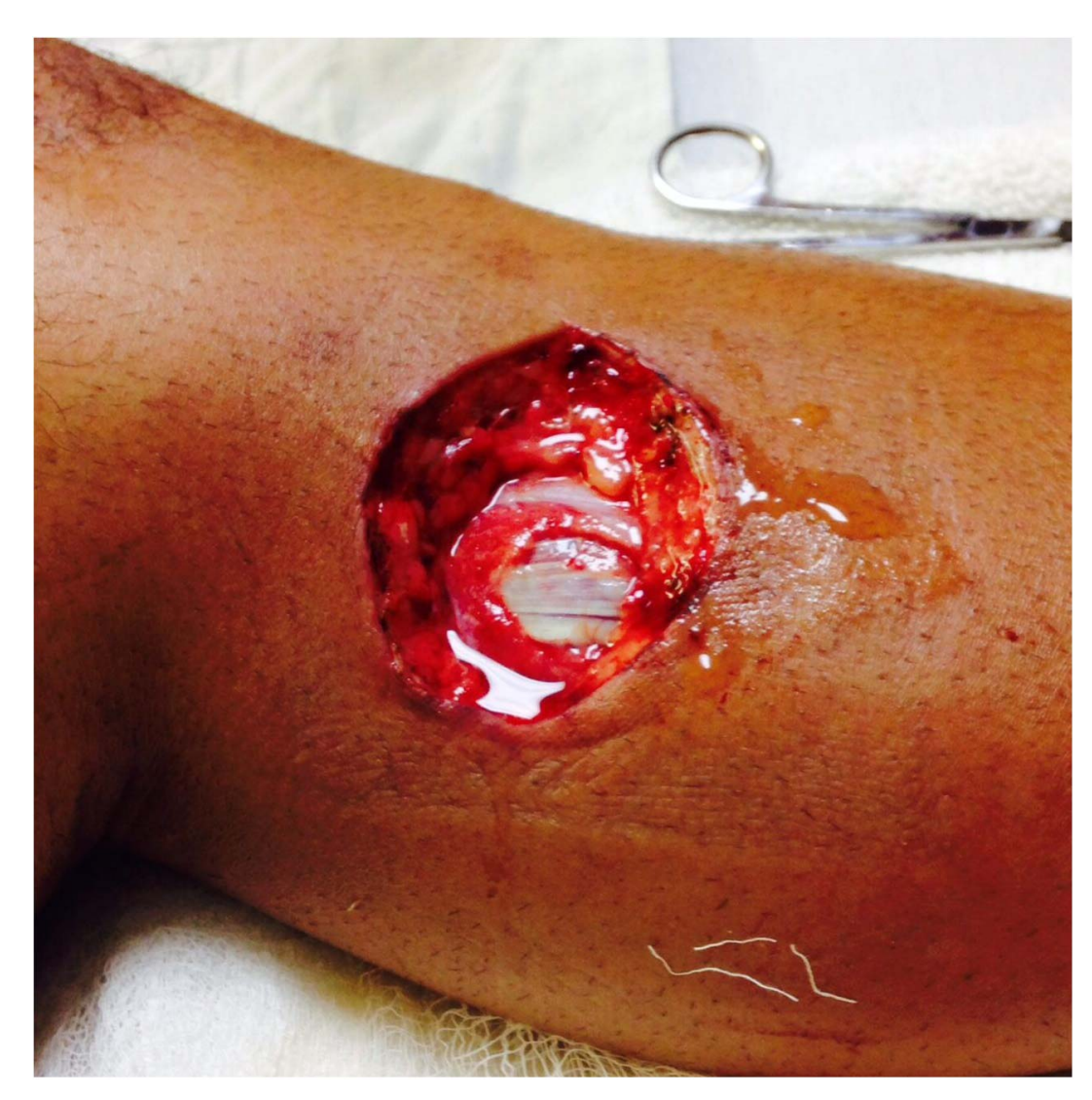

Beatty N, Al Mohajer M. BMJ Case Rep 2016. doi:10.1136/bcr-2015-213700 
Provenance and peer review Not commissioned; externally peer reviewed.

\section{REFERENCES}

1 Bonifaz A, Tirado-Sánchez A, Calderón L, et al. Cutaneous mucormycosis: mycological, clinical, and therapeutic aspects. Curr Fungal Infec Rep 2015.
2 Lelievre L, Garcia-Hermoso D, Abdoul H, et al. Posttraumatic mucormycosis: a nationwide study in France and review of the literature. Medicine (Baltimore) 2014;93:395-404.

3 Greenberg RN, Mullane K, van Burik JA, et al. Posaconazole as salvage therapy for zygomycosis. Antimicrob Agents Chemother 2006;50:126-33.

Copyright 2015 BMJ Publishing Group. All rights reserved. For permission to reuse any of this content visit

http://group.bmj.com/group/rights-licensing/permissions.

BMJ Case Report Fellows may re-use this article for personal use and teaching without any further permission.

Become a Fellow of BMJ Case Reports today and you can:

- Submit as many cases as you like

- Enjoy fast sympathetic peer review and rapid publication of accepted articles

- Access all the published articles

- Re-use any of the published material for personal use and teaching without further permission

For information on Institutional Fellowships contact consortiasales@bmjgroup.com

Visit casereports.bmj.com for more articles like this and to become a Fellow 